\title{
Asymmetric effects of shocks on TFP
}

\author{
Marcelo Arbex (University of Windsor) \\ Sidney Caetano (Federal University of Juiz de Fora) \\ Michel Souza (Federal University of Minas Gerais)
}

Working paper $17-02$

Working papers are in draft form. This working paper is distributed for purposes of comment and discussion only. It may not be reproduced without permission of the copyright holder. Copies of working papers are available from the author or at http://ideas.repec.org/s/wis/wpaper.html. 


\title{
Asymmetric effects of shocks on TFP
}

\author{
Marcelo Arbex* Sidney Caetano ${ }^{\dagger} \quad$ Michel Souza $^{\ddagger}$
}

March 21, 2017

\begin{abstract}
We study the TFP distribution and examine the non-stationarity of productivity series at various quantiles. Using the quantile autoregression unit root test, we find that the US TFP exhibits an asymmetric adjustment dynamics, i.e., positive and negative shocks might have different (permanent or temporary) effects on the TFP. Shocks dissemination depends on the local behavior of the TFP. We find that positive shocks have permanent effects on the TFP, while negative shocks can potentially have only transitory effects.
\end{abstract}

Keywords: TFP, Unit root tests, Quantile autoregression.

JEL Classification: C22, E32, O47.

${ }^{*}$ Corresponding author. Department of Economics, University of Windsor, 401 Sunset Avenue, Windsor, Ontario, Canada. E-mail address: arbex@uwindsor.ca. † Department of Economics, Federal University of Juiz de Fora, Brazil. E-mail address: sidney.caetano@ufjf.edu.br. $\ddagger$ Department of Economics, Federal University of Minas Gerais, Brazil. E-mail address: michelcs@ufmg.br. Any errors are our own. 


\section{Introduction}

The role of technology shocks as a source of business cycles is a central issue in the macroeconomics literature. While some authors have limited their attention to technology shocks that take the form of stationary disturbances to neutral productivity (Kydland and Prescott (1982), Heathcote and Perri (2002)), others have studied models in which technology shocks take the form of permanent disturbances to neutral productivity (King et al. (1988), Cogley and Nason (1995), and Rotemberg and Woodford (1996)). Rabanal et al. (2011) provides evidence that TFP processes for the US and the "rest of the world" are cointegrated. Schmitt-Grohe and Uribe (2011) identify that neutral and investment-specific productivity have a common stochastic trend (a novel source of aggregate fluctuations) and, moreover, total factor productivity (TFP) and the relative price of investment are cointegrated. On the other hand, Benati (2014)'s result from cointegration tests suggest that TFP and the relative price of investment are not cointegrated, irrespective of whether structural breaks in the series are allowed for. A key element of these studies is whether the US TFP process contains a unit root, thereby allowing for cointegration or not.

The stationarity vs. unit root question have important implications for the impact of negative and positive shocks on the TFP. However, it still remains to be verified if unit-root (nonstationarity) result survives when we consider the TFP distribution, and not only its conditional

mean. Our contribution is to test the unit root hypothesis of the US TFP using the quantile autoregression based unit root test (QAR) developed by Koenker and Xiao (2004) and extended by Galvao (2009). This methodology allows us to analyze the persistence of the TFP impact of positive and negative shocks and shocks of different magnitude. In particular high productivity periods may be viewed in the QAR context as data realizations in the higher conditional quantiles.

For reasons of robustness, our empirical analysis is based on three quarterly series for the US data produced by Rabanal et al. (2011), Schmitt-Grohe and Uribe (2011), and Fernald (2012). We study the TFP distribution and examine the non-stationarity of productivity series at various quantiles. Our results suggest that the TFP process exhibits an asymmetric adjustment dynamics, i.e., positive and negative shocks might have different (permanent or temporary) effects on the TFP. Overall the null hypothesis of unit root cannot be rejected for quantiles of the conditional TFP distribution. These results confirm that while positive shocks have permanent effects on the TFP (all samples), negative shocks can potentially have only temporary, transitory effects. At the lower tail of the TFP distribution, for particular quantiles (first and second samples) the unit root, non-stationarity hypothesis is rejected, suggesting transitory effects of negative shocks on the TFP. The evidence we present suggests that shocks dissemination depends on the local behavior of the TFP, an insight not yet explored in previous studies. 


\section{Methodology}

We assume that output $Y_{t}$ is produced according to a standard neoclassical production technology $F\left(K_{t}, A_{t} L_{t}\right)=K_{t}^{\theta}\left(A_{t} L_{t}\right)^{1-\theta}$, where $K_{t}$ is the capital stock, $L_{t}$ is the labor input, $A_{t}$ is the total factor productivity (TFP) and the capital share of output is $\theta=0.36$. The process of the $\log$ of $A_{t}$ (thereafter called TFP) can be constructed as follows (Rabanal et al. (2011)):

$$
\log \left(A_{t}\right)=\frac{\log \left(Y_{t}\right)-(1-\theta) \log \left(L_{t}\right)-\theta \log \left(K_{t}\right)}{1-\theta} .
$$

Following Koenker and Xiao (2004) and Galvao (2009) quantile autoregression based unit root test, an $\operatorname{AR}(\mathrm{q})$ process for the TFP at quantile $\tau$ with drift $\mu$ and deterministic trend $t$ is given by:

$$
\begin{aligned}
Q_{T F P_{t}}\left(\tau \mid T F P_{t-1}, T F P_{t-1}, \ldots, T F P_{t-k}\right)= & \alpha(\tau) T F P_{t-1}+\mu(\tau) \\
& +\gamma(\tau) t+\sum_{i=1}^{k-1} \phi_{i}(\tau) \Delta T F P_{t-i}
\end{aligned}
$$

where the $\tau^{t h}$ conditional quantile is defined as the value $Q_{T F P_{t}}\left(\tau \mid T F P_{t-1}, \ldots, T F P_{t-k}\right)$ such that the probability that the TFP conditional on its recent history will be less than $Q_{T F P_{t}}$ is $\tau$.

We test the unit root hypothesis for different quantiles $\tau$, i.e., unit root not only at the conditional mean of TFP, but also in the tails of the distribution. Let $\hat{\alpha}(\tau)$ be the quantile regression estimator and null hypothesis $H_{0}: \alpha(\tau)=1$ in equation (2). At any given quantile $\tau$, if $\alpha(\tau)=1$ then the series has a unit root and, therefore, shocks have permanent effects on TFP. If $\alpha(\tau)<1$ then the TFP is trend stationary, which means that shocks have temporary effects only.

Using the results derived by Koenker and Xiao (2004) and Galvao (2009), we find the values of the t-statistic $t_{n}(\tau)$ for $\hat{\alpha}(\tau)$ for different quantile levels

$$
t_{n}(\tau)=\frac{f\left(\widehat{F^{-1}(\tau)}\right)}{\sqrt{\tau(1-\tau)}}\left(Y_{-1}^{T} P_{X} Y_{-1}\right)^{\frac{1}{2}}(\hat{\alpha}(\tau)-1)
$$

where $f$ and $F$ are the probability and cumulative density functions of error term, respectively, $Y_{-1}$ is the vector of lagged log-TFP, $P_{X}$ the projection matrix onto the space orthogonal to $X=\left(1, t, \Delta T F P_{t-1}, \ldots, \Delta T F P_{t-k+1}\right)$, and $f\left(F^{-1}(\tau)\right)$ is estimated according to a rule proposed in Koenker and Xiao (2004). 


\section{Results}

We study three alternative quarterly series for the US data produced by Rabanal et al. (2011), Schmitt-Grohe and Uribe (2011), and Fernald (2012). The sample periods for these series are 1973:Q1-2006:Q4, 1948:Q1-2006:Q4, and 1948:Q1-2016:Q3, respectively. ${ }^{1}$ Figure 1 shows estimates of $\alpha(\tau)$ for $\tau=0.05,0.10, \ldots, 0.95$ together with $95 \%$ bootstrapped confidence bands (gray area). ${ }^{2}$ It presents the estimates of the persistence, constant and trend parameters, as well as the estimated parameters (horizontal dashed line) from a simple mean regression with $95 \%$ confidence bands (dotted line).

The persistence parameter estimates are increasing along the quantiles. The point values of the persistence parameter ranges from $0.761-1.092,0.9269-1.018$ and $0.965-1.002$ in the first, second and third samples, respectively. This parameter value is close to one in the upper tail of the conditional TFP distribution. More precisely, it is one at the quantile 0.85 (first sample), quantile 0.75 upwards (second sample) and at quantile 0.80 (third sample). Figures 1a-1c clearly shows that (i) the persistence parameter estimate is different than one along the conditional TFP distribution and (ii) it is lower than the OLS estimate for low quantiles and higher for high quantiles and (iii) $\hat{\alpha}(\tau)$ increases when we move from lower to higher quantiles.

The TFP appears to exhibit an asymmetric adjustment dynamics. Using the QAR approach, we find that positive and negative shocks have different - permanent or temporary - effects on the TFP. The autoregressive coefficient values at the lower quantiles are smaller than those at higher quantiles, suggesting that the local behavior of the TFP to a negative shock would be more stationary than its behavior during an expansion. Considering the first two samples (Figures 1a1b), positive shocks are more likely to have permanent effect on the TFP. On the other hand, using Fernald (2012)'s sample (Figure 1c) we find that persistence parameter estimates are closer to one for all quantiles considered, which implies that both positive and negative shocks have permanent effects. $^{3}$

Table (I) presents the point estimates, the t-statistics and the critical values for the $5 \%$ significance level as we test the null hypothesis $H_{0}: \alpha(\tau)=1$ for $\tau=0.05,0.10, \ldots, 0.95$ using the t-statistic based on equation (2). Overall the null hypothesis cannot be rejected - the t-statistic is numerically greater than the critical value for all quantiles in the third sample and for most of the first and second samples. These results confirm that, in general, shocks have permanent effects

\footnotetext{
${ }^{1}$ For Rabanal et al. (2011)'s series, see their methodology section. The series of total factor productivity of Schmitt-Grohe and Uribe (2011) is taken from Beaudry and Lucke (2010). This time series covers the nonfarm business sector and it is adjusted for variations in capital capacity utilization. The original series of Fernald (2012) is the factor-utilization-adjusted TFP series. It is obtained from John Fernald's website and is provided in terms of annualized percentage changes (i.e., 400 times changes in its logarithm). The quarterly TFP series in levels is recovered by dividing the original series by 400 and then cumulating the resulting series (Nam and Wang (2015)).

${ }^{2}$ We choose the lag length based on the MAIC criterion suggested by Ng and Perron (2001).

${ }^{3}$ Hosseinkouchack and Wolters (2013) find that shocks either positive or negative, including large recessionary shocks have permanent effects on the real US GDP. Castro (2013) finds that the effect of the international financial crisis on the labor productivity in the United States is mainly due to a strong reduction of the TFP.
} 
Figure 1: Quantile Autoregression: Persistence, Constant and Trend

(a) Rabanal et al. (2011) - 1973:Q1 - 2006:Q4
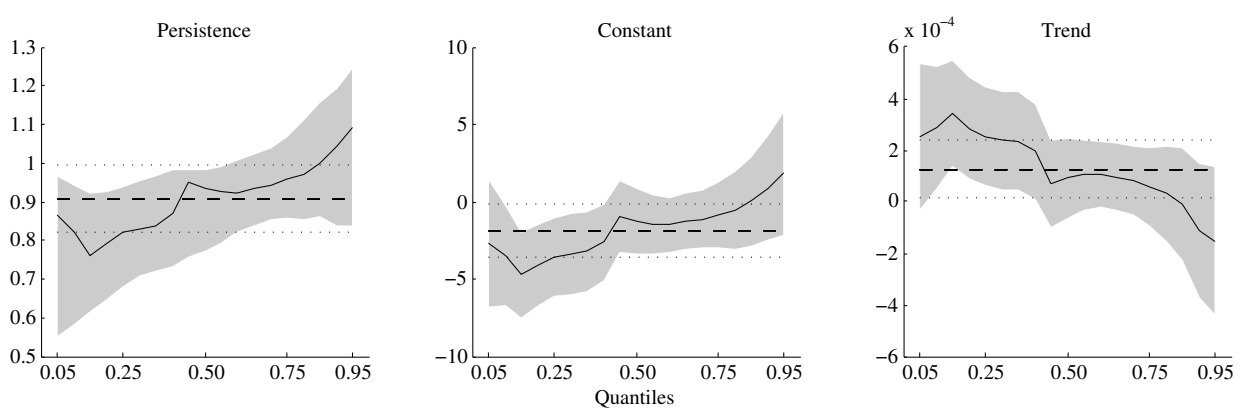

(b) Schmitt-Grohe and Uribe (2011) - 1948:Q1 - 2006:Q4
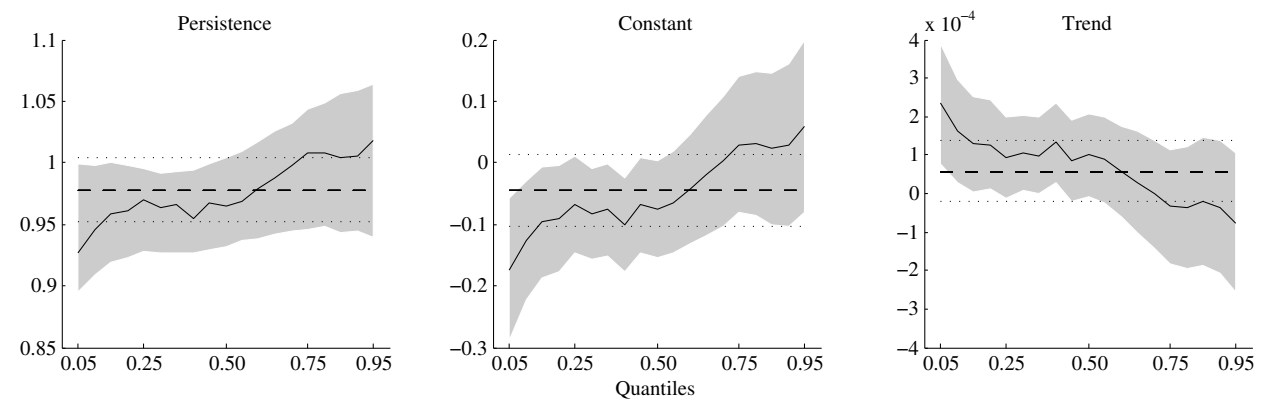

(c) Fernald (2012) - 1948:Q1 - 2016:Q3
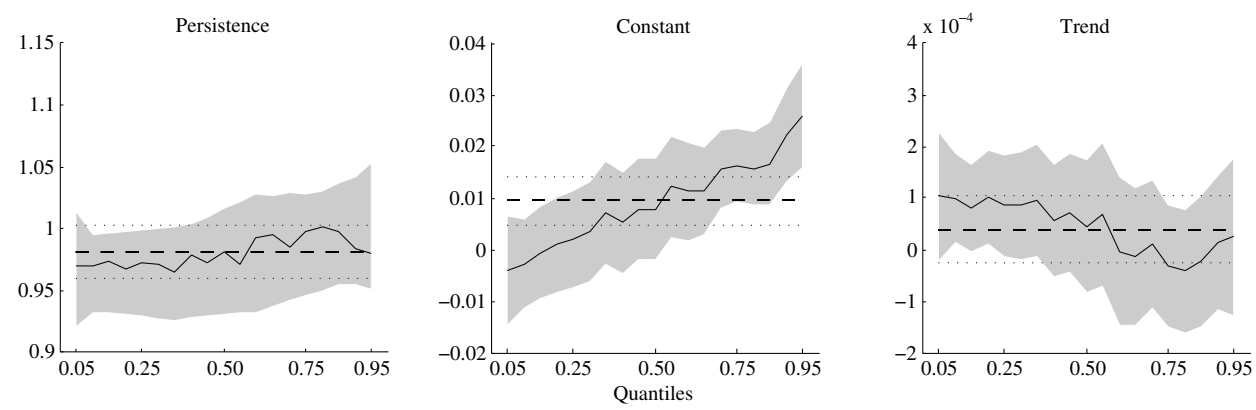

Note: The graphs show estimates of the Persistence and Deterministic Parameters at different Quantiles. The Grey areas indicate 95\% Bootstrapped Confidence

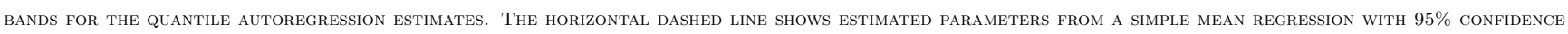
BANDS (DOTTED) FOR COMPARISON.

on the TFP. However, at the lower tail of the TFP distribution, for particular quantiles - 0.15, 0.20 and 0.35 (first sample) and 0.05 (second sample) - the unit root, non-stationarity hypothesis is rejected, suggesting some transitory effects of negative shocks on these TFP processes.

\section{Conclusions}

Using quantile based unit root test, we study the TFP distribution and examine the nonstationarity of productivity series at various quantiles. A key insight of this paper is to consider asymmetric effects of shocks of different size and magnitude on the TFP. Our results show that while positive shocks have permanent effects on the TFP, negative shocks can potentially have 
Table I: Unit Root Test Results

\begin{tabular}{|c|c|c|c|c|c|c|c|c|c|}
\hline & \multicolumn{3}{|c|}{ 1973:Q1 - 2006:Q4 } & \multicolumn{3}{|c|}{ 1948:O1 - 2006:O4 } & \multicolumn{3}{|c|}{ 1948:Q1 - 2016:Q3 } \\
\hline & & & Critical & & & Critica & & & Critica \\
\hline Quantile & $\hat{\alpha}$ & t-stat & Value & $\hat{\alpha}$ & t-stat & Value & $\hat{\alpha}$ & t-stat & Value \\
\hline 0.05 & 0.866 & -2.149 & -3.092 & $0.927^{*}$ & -2.808 & -2.681 & 0.970 & -1.406 & -2.310 \\
\hline 0.10 & 0.823 & -2.016 & -2.895 & 0.946 & -2.466 & -2.674 & 0.970 & -1.815 & -2.829 \\
\hline 0.15 & $0.761^{*}$ & -2.963 & -2.895 & 0.959 & -1.955 & -2.933 & 0.974 & -2.057 & -2.821 \\
\hline 0.20 & $0.794 *$ & -2.870 & -2.743 & 0.961 & -2.136 & -2.855 & 0.967 & -2.501 & -3.075 \\
\hline 0.25 & 0.819 & -2.743 & -2.756 & 0.971 & -1.700 & -2.942 & 0.972 & -2.123 & -3.190 \\
\hline 0.30 & 0.829 & -2.700 & -2.896 & 0.963 & -2.192 & -2.762 & 0.971 & -2.154 & -3.042 \\
\hline 0.35 & $0.839^{*}$ & -3.119 & -2.806 & 0.966 & -2.173 & -2.804 & 0.965 & -2.439 & -3.135 \\
\hline 0.40 & 0.868 & -2.647 & -2.969 & 0.954 & -2.841 & -2.927 & 0.979 & -1.364 & -3.115 \\
\hline 0.45 & 0.952 & -0.989 & -2.866 & 0.968 & -2.130 & -2.974 & 0.973 & -1.867 & -3.137 \\
\hline 0.50 & 0.934 & -1.496 & -2.800 & 0.965 & -2.242 & -3.154 & 0.981 & -1.140 & -3.186 \\
\hline 0.55 & 0.925 & -1.821 & -2.825 & 0.969 & -1.819 & -3.133 & 0.971 & -1.846 & -3.131 \\
\hline 0.60 & 0.924 & -1.743 & -2.770 & 0.979 & -1.234 & -3.138 & 0.993 & -0.448 & -3.122 \\
\hline 0.65 & 0.936 & -1.567 & -2.689 & 0.988 & -0.705 & -3.212 & 0.996 & -0.268 & -3.052 \\
\hline 0.70 & 0.943 & -1.101 & -2.751 & 0.998 & -0.113 & -3.277 & 0.985 & -0.975 & -2.937 \\
\hline 0.75 & 0.957 & -0.648 & -2.851 & 1.009 & 0.352 & -3.207 & 0.998 & -0.124 & -2.899 \\
\hline 0.80 & 0.971 & -0.407 & -2.475 & 1.008 & 0.323 & -2.978 & 1.002 & 0.116 & -3.014 \\
\hline 0.85 & 1.002 & 0.002 & -2.579 & 1.004 & 0.173 & -3.012 & 0.998 & -0.136 & -2.788 \\
\hline 0.90 & 1.044 & 0.429 & -2.651 & 1.006 & 0.208 & -2.597 & 0.985 & -0.697 & -2.665 \\
\hline 0.95 & 1.092 & 1.349 & -2.358 & 1.018 & 1.247 & -2.405 & 0.980 & -0.986 & -2.310 \\
\hline
\end{tabular}

Note: The table shows point estimates, t-statistic and critical values for the $5 \%$ significance level. If t-statistic is numerically smaller than the critical value then we reject $\left(^{*}\right) H_{0}: \alpha(\tau)=1$ at the $5 \%$ level.

only temporary, transitory effects. This potential asymmetry of the TFP distribution to shocks has important consequences for economic and policy analysis as well as for previous and future research.

\section{References}

Beaudry, P. And B. Lucke (2010): "Letting Different Views about Business Cycles Compete," in NBER Macroeconomics Annual 2009, Volume 24, National Bureau of Economic Research, Inc, NBER Chapters.

Benati, L. (2014): "Do TFP and the relative price of investment share a common I(1) component?" Journal of Economic Dynamics and Control, 45, 239 - 261.

Castro, D. F. (2013): "An international comparison of the impact of the 2008 crisis on productivity," Applied Economics Letters, 20, 1263-1269. 
Cogley, T. And J. Nason (1995): "Output Dynamics in Real-Business-Cycle Models," American Economic Review, 85, 492-511.

FERnALD, J. G. (2012): "A quarterly, utilization-adjusted series on total factor productivity," Working Paper Series 2012-19, Federal Reserve Bank of San Francisco.

GalvaO, A. F. (2009): "Unit root quantile autoregression testing using covariates," Journal of Econometrics, 152, $165-178$.

HeAthcote, J. And F. Perri (2002): "Financial autarky and international business cycles," Journal of Monetary Economics, 49, 601-627.

Hosseinkouchack, M. And M. Wolters (2013): "Do large recessions reduce output permanently?" Economics Letters, 121, 516-519.

King, R., C. Plosser, and S. Rebelo (1988): "Production, growth and business cycles: II. New directions," Journal of Monetary Economics, 21, 309-341.

Koenker, R. And Z. Xiao (2004): "Unit Root Quantile Autoregression Inference," Journal of the American Statistical Association, 99, 775-787.

Kydland, F. E. And E. C. Prescott (1982): "Time to Build and Aggregate Fluctuations," Econometrica, 50, 1345-70.

NAM, D. AND J. WANG (2015): "The effects of surprise and anticipated technology changes on international relative prices and trade," Journal of International Economics, 97, 162 - 177.

NG, S. ANd P. Perron (2001): "LAG Length Selection and the Construction of Unit Root Tests with Good Size and Power," Econometrica, 69, 1519-1554.

Rabanal, P., J. F. Rubio-RamÃrez, and V. Tuesta (2011): "Cointegrated TFP processes and international business cycles," Journal of Monetary Economics, 58, 156 - 171.

RotemberG, J. And M. Woodford (1996): "Real-Business-Cycle Models and the Forecastable Movements in Output, Hours, and Consumption," American Economic Review, 86, 71-89.

Schmitt-Grohe, S. And M. Uribe (2011): "Business Cycles With A Common Trend in Neutral and Investment-Specific Productivity," Review of Economic Dynamics, 14, 122-135. 